\title{
Muscle adaptation to sleeve gastrectomy: Potential role of nutritional supplementation and physical exercise
}

\author{
Entesar Ali Saber ${ }^{*}$, Neven Makram Aziz $2^{2 *}$, Mohammed Mustafa Abd El Aleem ${ }^{3 *}$, \\ Maha Yehia Kamel 4 , Seham A Abd El-Aleem¹, Fatma Farrag Ali², Doaa Mohamed Elroby Ali ${ }^{5}$ \\ and Amira Fathi Behery ${ }^{1}$
}

'Department of Histology and Cell Biology, Minia University Faculty of Medicine, Minia, Egypt; ${ }^{2}$ Department of Medical Physiology, Minia University Faculty of Medicine, Minia, Egypt; ${ }^{3}$ Department of Anatomy, Minia University Faculty of Medicine, Minia, Egypt; ${ }^{4}$ Department of Pharmacology, Minia University Faculty of Medicine, Minia, Egypt; ${ }^{5}$ Department of Biochemistry, Sohag University, Faculty of Pharmacy, Sohag, Egypt

Skeletal muscle is metabolically and functionally flexible and contractile under normal conditions. Obesity is a risk factor that causes metabolic disorders and reduces muscle contractility. Sleeve gastrectomy (SG) has been used for surgical correction of obesity. This work aimed to investigate how obesity and its surgical correction affects skeletal muscle and the possible role of nutritional supplementation and physical exercise. Adult male albino rats were randomly divided into five groups, 8 rats per group: group la (control non-obese), group lb (control obese), group II (post-operative, SG), group III (post SG + nutritional supplementation) and group IV (post SG + nutritional supplementation + physical exercise). SG resulted in cellular and metabolic degenerative disorders in the muscle including wasting, weakness and fibrosis with elevated inflammatory, oxidative and injury markers. Nutritional supplementation induced the post SG muscle regeneration indicated by high expression of insulin growth factor-1 (IGF-1) and myogenin and low expression of transforming growth factor beta 1 (TGF- $\beta 1$ ). Interestingly, it improved the metabolic state of the muscle by reducing the oxidative stress, inflammatory and muscle injury markers and delaying the onset of fatigue. What is more, physical exercise along with nutritional supplementation resulted in further improvement of the muscle metabolic state and function. In conclusion, nutritional supplementations together with physical exercise after SG are essential for preserving muscle mass and contractility and improving its metabolic and functional status.

Keywords: gastrocnemius muscle, sleeve gastrectomy, nutritional supplementation, physical exercise, insulin growth factor-1, myogenin.

Received: 06 December, 2020; revised: 08 February, 2021; accepted: 27 February, 2021; available on-line: 22 December, 2021

凶e-mail: emadmax71@yahoo.com

*Delegated to Deraya University, New Minia City

Abbreviations: IGF-1, insulin growth factor- 1 ; TGF- $\beta 1$, transforming growth factor beta 1; SG, sleeve gastrectomy

\section{INTRODUCTION}

Obesity is one of the most important risk factors causing metabolic disorders that predispose to heart diseases, hypertension and diabetes (Gobl et al., 2017). Obesity affects muscle functions and with aging increases morbidity and mortality (Tallis et al., 2018).
Obese individuals usually tend to use mineral and vitamin supplementation to get a balanced diet (Ali et al., 2019). Calcium and vitamin D supplementation for correcting obesity-related vitamin $\mathrm{D}$ deficiency improves muscle mass and has an appetite-suppressing effect that helps reduce weight (Petroni et al., 2019).

Tallis and others (Tallis et al., 2018) reported that 6-weeks dietary intervention reversed the adverse changes in muscle function caused by essential fatty acids deficient diet. In contrast, a similar dietary intervention failed to reverse obesity-related changes in skeletal muscle function although improved the metabolic state (Seebacher et al., 2017). These treatment regimens reduce body weight, improve insulin sensitivity and control of blood sugar level, thus, are effective over a short time. Therefore, they are difficult to maintain as lifestyle changes and often unrealistic to manage the disease in the long term. Recently, surgical interventions that alter intestinal physiology were found to be more effective. Though its durability remains unclear, the approach may be the best one for successful, long-term management of body weight and obesity-related chronic diseases. Currently, the two most popular bariatric surgeries are gastric bypass surgery (RYGB) and gastrectomy (SG). Both approaches result in significant weight loss and blood sugar control in humans and animals (Sinclair et al., 2018).

Despite the multiple clinical benefits, a number of surgical and digestive complications can occur after bariatric procedures. The potential complications include undernutrition that can develop as a result of reduced intake of macronutrients and micronutrients, with subsequent development of anemia and protein malnutrition (Lupoli et al., 2017).

Physical exercise is nowadays an indispensable component of a healthy lifestyle able to reduce the risk of developing cardiovascular, endocrine, muscular and immunity disorders. Regular physical activity can counteract the negative effects and toxicity of oxidative stress that develops with aging (Simioni et al., 2018).

The aim of this study was to investigate the molecular, cellular and physiological adaptation of the gastrocnemius muscle to SG. Moreover, we studied the possible role of nutritional supplementation and physical exercise in improving the muscle state following SG. The muscle was assessed using biochemical markers, electrical stimulation response technique, gene expression study, histological and immunohistochemical techniques. 


\section{MATERIAL AND METHODS}

\section{Animals}

Sixty Sprague Dawley rats (3 weeks old, 95-100 g body weight) from the National Research Centre (Giza, Egypt) were kept under standard laboratory conditions with natural day/night cycle. Rats were housed in cages measuring $45 \times 40 \times 65 \mathrm{~cm}$, fed commercial rat chow and left freely wandering for one week before the onset of the study. After one week, the body weight and the food consumed (initial food intake) were measured weekly for 6 weeks. The choice of the duration in the present experiment was based on the previous finding of (Brinckerhoff et al., 2013) who reported that six weeks in rats are equivalent to 3 years of human life.

Rats were divided into two categories: normal nonobese rats (10 rats) received a standard diet and the obese group (50 rats) received a high-fat diet (HFD). After the 6 weeks, Lee index was calculated for each rat according to the formula:

$$
\text { Lee index }=\sqrt[3]{\frac{\text { Body weight in gram }}{\text { Naso-anal length in } \mathrm{mm}}} x 10000
$$

Only forty-five rats fed with HFD had a Lee index $\geq 0.3$ and were considered obese (Campos et al., 2008) and, subsequently, divided into four groups plus control non-obese group (8 rats each after calculating the mortality rate) for further 6 weeks.

Finally, the rats were divided into the following groups:

Group Ia (10 rats): control non-obese rats fed a commercial standard diet.

Group Ib (10 rats): control obese rats fed an HFD.

Group II (15 rats): obese rats subjected to sleeve gastrectomy "SG" and then fed a standard diet with no further treatment. Only 8 rats survived the surgery (survival rate $=50 \%$ ).

Group III (10 rats): obese rat which undergone SG fed a standard diet supplemented with an oral daily dose of sodium selenite $(0.05 \mathrm{mg} / \mathrm{kg}$, Sigma) (Zhang et al., 2018) plus "vitamin B complex" (9.036 mg/kg, Amriya Pharmaceuticals, Egypt) (Ibrahim et al., 2017), vitamin D (2000 IU, Sigma), and calcium (500 mg/kg, Minapharm Pharmaceuticals) (Alatawi et al., 2018). In addition, each animal was gavaged orally with protein/ essential amino acids (rich in leucine, $1.35 \mathrm{~g} / \mathrm{kg}$ body weight) (Crozier et al., 2005). Two rats died post-operation (survival rate $=80 \%$ ).

Group IV (10 rats): obese rats which underwent SG and were fed a standard diet with the same supplementation as group III. In addition, equipped cages were used for housing post-operative rats until the end of the experiment (physical exercise equipment) according to the method of Makowska and Weary (Makowska \& Weary, 2016) with modification. Two rats died post-operation (survival rate $=80 \%$ ).

\section{Diet protocol}

The standard diet ( $\mathrm{g} / \mathrm{kg}$ diet) formula was prepared as in Davidson and others (Davidson et al., 2012). HFD contained $20 \mathrm{~g}$ of fat $/ 100 \mathrm{~g}$ of the diet and provided $4.1 \mathrm{kcal} / \mathrm{g}$ of the diet (Hariri \& Thibault, 2010). Standard diet and HFD constituents were purchased from ElGomhoria Company, Cairo, Egypt.

\section{Body mass index (BMI)}

BMI was done with light ether according to the method of Rabiu and others (Rabiu et al., 2017). It was calculated weekly according to the formula: BMI = body weight $(\mathrm{g}) /$ length ${ }^{2}\left(\mathrm{~cm}^{2}\right)$.

\section{Sleeve gastrectomy}

Thirty-five obese rats were abstained from solid food for 12 hours and allowed access to water the day prior to the surgery. Rats subjected to SG were anaesthetized with an intra-peritoneal injection of sodium pentobarbital $(60 \mathrm{mg} / \mathrm{kg}$ of body weight) according to the method of Valenti and others (Valenti et al., 2011). Post SG, rats were fed a liquid diet ( $5 \%$ glucose $+0.9 \%$ normal saline) for two days. On the third postoperative day, animals resumed regular rat chow and water ad libitum and treated groups were given the supplementation (Teive et al., 2012).

\section{Electric stimulation of the right gastrocnemius muscle}

After 6 weeks of the treatment and following overnight fasting, rats were anesthetized with urethane (1.5 g/kg; i.p.) and fixed to a dissection board as previously described by MacIntosh and others (MacIntosh et al., 2011). Force of contraction was recorded on a calibrated chart of oscillograph (Bioscience, USA). The maximal force $(\mathrm{F})$ reached was determined from the calibrated chart. The time till 50\% fatigue was determined according to the speed of the chart recorded by the oscillograph.

\section{Biochemical analysis}

After electrical stimulation forty rats were decapitated, blood samples were collected and sera were separated and stored at $-80^{\circ} \mathrm{C}$ and both gastrocnemius muscles were excised for further analysis.

\section{Serology}

Glucose concentration was determined using enzymatic colorimetric methods (Bio-Diagnostic kits, Egypt).

Insulin concentration was assayed using an enzymelinked immunosorbent assay (ELISA) kit (Calbiotech, USA).

Triglycerides (TGs), low-density lipoprotein cholesterol (LDL-c) and high-density lipoprotein cholesterol (HDL-c) levels were determined using enzymatic colorimetric methods (Bio-Diagnostic kits, Egypt). The atherogenic index was calculated according to Ikewuchi and others (Ikewuchi et al., 2014).

Albumin concentration was determined using the enzymatic colorimetric method (Spinreact SAU, Spain).

$\mathrm{Ca}^{+2}$ concentration was determined by enzymatic colorimetric method, using kits purchased from BioSystems, Spain.

25-hydroxyvitamin D was assayed using enzyme-linked immunosorbent assay (ELISA) kit (ALPCO, USA).

\section{Molecular assessment of the muscle}

The known weight of the right stimulated and its corresponding left gastrocnemius muscle were homogenized in phosphate buffer saline, centrifuged and the supernatants were used for determination of malondialdehyde (MDA) concentration as previously described Ohkawa and others (Ohkawa et al., 1979); tumor necrosis factor- $\alpha$ $(\mathrm{TNF}-\alpha)$ concentration was estimated by ELISA kit (Lab Vision Corporation, USA) according to the manufac- 
Table 1. The primers sequences for IGF-1 and reference gene.

\begin{tabular}{lll}
\hline Gene title & Forward primer 5'-3' & Reverse primer 5'-3' \\
\hline IGF-1 & 5'-AGC TGA GAT AGT GTT TCC CAA AGG-3' $^{\prime}$ & 5'-TTC CAA ACG CGA AAT GAA TG-3' \\
\hline GAPDH & $5^{\prime}$-CCT TCC GTG TTC CTA CC-3' & 5-'AGG ATG CCC TTा AGT GG-3' \\
\hline
\end{tabular}

turer's instructions and muscle creatine kinase $(\mathrm{CK})$ concentration using colorimetric kit (ElabScience, China). In addition, muscle glycogen level was determined by sulfuric acid method adopted by Ramu and others (Ramu et al., 2016).

\section{Assessment of muscle Insulin Growth Factor (IGF-1) RNA}

Total RNA was isolated from the known weight of the left gastrocnemius muscle specimens using RNA isolation kit (RiboZol ${ }^{\mathrm{TM}}$ RNA Extraction Reagents, AMRESCO, LLC, Solon, Ohio, USA). High-quality RNA (A260/280 $\geq 1.6$ ) was selected and used for quantitative real-time PCR and IGF-1 (Insulin growth factor-1, regeneration marker) and $\mathrm{GAPDH}$ genes were selected as target and internal reference gene, respectively. The sequence of the gene of interest was obtained from NCBI database and primers were designed via Thermo Fisher Scientific. Quantitative real-time PCR was performed using the One-Step TaqProbe qRT-PCR Kit (Applied Biological Materials, Canada). The sequence of the primers used in this study were summarized in $\mathrm{Ta}$ ble 1. TaqMan qRT-PCR gene expression assays were conducted in $0.1 \mathrm{ml}$ fast tubes according to the manufacturer's instructions, in a final volume of $50 \mu \mathrm{l}$. Thermal cycling was performed in the Bioer thermocycler using the following cycling conditions: $50^{\circ} \mathrm{C}$ for $1 \mathrm{~min}$, $95^{\circ} \mathrm{C}$ for $10 \mathrm{~min}$, and 40 cycles at $95^{\circ} \mathrm{C}$ for $15 \mathrm{~s}$ and $60^{\circ} \mathrm{C}$ for $1 \mathrm{~min}$.

\section{Histological and Immunohistochemical Examination}

The remaining part of the gastrocnemius muscle of the left hind-limb of each rat was fixed in $10 \%$ formal saline and processed for histological and immunohistochemical evaluation. Paraffin sections were stained with hematoxylin and eosin (H\&E), Masson trichrome, Glees method (for nerve fibers) and immunohistochemical markers: myogenin (Halevy et al., 2004), and transforming growth factor beta 1 (TGF- $\beta 1$ ) (Delaney et al., 2017). The second piece of the muscle was rapidly transferred to the cryostat for histochemical staining of succinate dehydrogenase as an indicator of the mitochondrial oxidative capacity (Chinopoulos, 2013) and acetylcholine esterase (AChE) as an important component of all cholinergic synapses in the central and peripheral nervous system (Bancroft \& Gamble, 2008).

\section{Morphometric analysis}

For the morphometric analysis, an unbiased sampling procedure was applied. Four blocks/animal were used for cross and longitudinal sectioning. Blocks were randomly selected for serial sectioning and H\&E stained for the light microscope examination (Olympus CX-31, Tokyo, Japan, equipped with ImageJ software). Morphometric analysis was performed on a cross and longitudinal section for each block on three randomly selected microscopic fields/section and the following parameters were obtained:

- The mean number of muscle fibers (the muscle mass).

- The mean number of cells expressing myogenin protein.

- The volume density $(\mathrm{Vv})$ of the three types of muscle fibers and of collagen fibers.

- The cross sectional area of the muscle fibers (CSA).

\section{Statistical analysis}

Data were represented as means (for 8 rats after omitting the dead rats) \pm standard error of the mean (S.E.M.). Statistical analysis was performed and the significancy of differences between the groups was assessed by one-way ANOVA followed by Tukey-Kramer posthoc test for multiple comparisons with a value of $P<0.05$ considered statistically significant .

\section{RESULTS}

\section{Survival rate}

The survival rate for the SG group (group II) was $50 \%$ due to marked loss of appetite resulting in wasting and death. Deaths occurred in post SG treated groups (III and IV) during anesthesia, surgery, or the first hours following surgery due to sepsis.

\section{Assessment of the BMI and food intake}

As shown in Table 2, the present study revealed that the initial BMI of all experimental groups were significantly higher compared with that of group Ia. In addition, group $\mathrm{Ib}$ showed the highest significance while group II showed the lowest significance of the final BMI as compared with the all experimental groups and with its initial values. The final BMI of group III showed a

Table 2. BMI and food intake in all experimental groups.

Data are expressed as mean \pm S.E.M. of 8 rats per group. BMI: Body mass index. a: significantly different from group la, b: significantly different from its corresponding group, c: significantly different from the final value of group la, $P \leq 0.05$.

\begin{tabular}{|c|c|c|c|c|}
\hline \multirow{2}{*}{$\begin{array}{l}\text { Parameters } \\
\text { Groups }\end{array}$} & \multicolumn{2}{|l|}{ BMI } & \multicolumn{2}{|c|}{ Food intake $(\mathrm{g} / \mathrm{d})$} \\
\hline & Initial & Final & Initial & Final \\
\hline Group la & $0.55 \pm 0.01$ & $0.62 \pm 0.03$ & $15.1 \pm 1.3$ & $13.9 \pm 0.24$ \\
\hline Group Ib & $0.69 \pm 0.02^{a}$ & $0.88 \pm 0.02^{b c}$ & $19.9 \pm 1.4^{a}$ & $13.5 \pm 0.2^{b}$ \\
\hline Group II & $0.67 \pm 0.01^{a}$ & $0.44 \pm 0.01^{b c}$ & $18.9 \pm 0.9^{a}$ & $9.1 \pm 0.4^{b c}$ \\
\hline Group III & $0.70 \pm 0.02^{\mathrm{a}}$ & $0.53 \pm 0.01^{b c}$ & $19.2 \pm 1.1^{a}$ & $11.3 \pm 0.1^{b c}$ \\
\hline Group IV & $0.73 \pm 0.02^{a}$ & $0.65 \pm 0.01^{b}$ & $19.6 \pm 1.2^{\mathrm{a}}$ & $12.6 \pm 0.1^{b c}$ \\
\hline
\end{tabular}


Table 3. The serum parameters in the different experimental groups.

Data are expressed as mean \pm S.E.M. of 8 rats per group. a: significantly different from group la, b: significantly different from group Ib, c: significantly different from group II, d: significantly different from group III, $P \leq 0.05$. TGs: Triglycerides; HDL: High-density lipoproteins; LDL: Low-density lipoproteins.

\begin{tabular}{|c|c|c|c|c|c|}
\hline $\begin{array}{l}\text { Groups } \\
\text { Parameters }\end{array}$ & Group la & Group Ib & Group II & Group III & Group VI \\
\hline TGs (mg/dl) & $44.4 \pm 1.6$ & $98.3 \pm 2.1^{\mathrm{a}}$ & $42.5 \pm 1.5^{b}$ & $45.1 \pm 1.7^{b}$ & $44.5 \pm 1.8^{b}$ \\
\hline $\mathrm{HDL}-\mathrm{c}(\mathrm{mg} / \mathrm{dl})$ & $56.5 \pm 1.4$ & $32.4 \pm 1.3^{a}$ & $54.8 \pm 1.4^{b}$ & $55.8 \pm 1.5^{b}$ & $62.8 \pm 1.7^{a b}$ \\
\hline LDL-c (mg/dl) & $24.5 \pm 1.2$ & $50.2 \pm 1.7^{a}$ & $21.5 \pm 1.3^{b}$ & $26.5 \pm 1.3^{b}$ & $21.5 \pm 1.3^{b}$ \\
\hline Atherogenic index & $-0.1 \pm 0.001$ & $0.5 \pm 0.007^{a}$ & $-0.1 \pm 0.007^{b}$ & $-0.09 \pm 0.009^{b}$ & $-0.15 \pm 0.005^{a b}$ \\
\hline Fasting glucose (mg/dl) & $98.1 \pm 0.7$ & $210.2 \pm 2.1^{a}$ & $90.6 \pm 0.5^{\mathrm{ab}}$ & $99.3 \pm 0.9 \mathrm{bc}$ & $96.4 \pm 0.8^{b c}$ \\
\hline Insulin (mIU/I) & $7.4 \pm 0.21$ & $9.3 \pm 0.15^{a}$ & $6.4 \pm 0.11^{a b}$ & $7.1 \pm 0.24 \mathrm{bc}$ & $7.7 \pm 0.31^{b c}$ \\
\hline Albumin (g/dl) & $4.2 \pm 0.1$ & $3.6 \pm 0.2^{\mathrm{a}}$ & $2.9 \pm 0.1^{\mathrm{ab}}$ & $4.1 \pm 0.1^{b c}$ & $4.5 \pm 0.2^{b c}$ \\
\hline $\mathrm{Ca}^{+2}$ concentration (mg/dl) & $9.5 \pm 0.16$ & $8.1 \pm 0.11^{a}$ & $7.5 \pm 0.12^{\mathrm{ab}}$ & $9.2 \pm 0.14^{b c}$ & $9.8 \pm 0.15^{b c}$ \\
\hline 25-hydroxyvitamin D (ng/dl) & $26.5 \pm 0.3$ & $19.7 \pm 0.1^{a}$ & $18.5 \pm 0.2^{\mathrm{ab}}$ & $24.5 \pm 0.4^{b c}$ & $28.5 \pm 0.5^{b c}$ \\
\hline
\end{tabular}

lower significance level as compared with groups Ia and $\mathrm{Ib}$ and with its initial values. While the final BMI of group IV showed a lower significance from its initial BMI but the remaining showed insignificant difference when compared with final BMI of group Ia. This was accompanied with a significantly higher initial food intake of all experimental groups as compared with group Ia but the final food intake showed significantly lower values in all experimental groups except group Ib that was still insignificant compared to final food intake of group Ia.

\section{Assessment of the serum parameters}

As shown in Table 3, group Ib showed atherogenic serum lipid profile. There were significant higher values in the TGs and LDL-c with a significant lower value in HDL-c level and a significant higher value in the atherogenic index as compared with all experimental groups.
Contrary, groups II and III showed insignificant differences in all serum lipid profile as compared to group Ia while group IV showed a significant higher value in HDL-c with insignificant difference in TGs and LDL-c levels.

As regard serum fasting glucose and insulin, group Ib showed significant highest values and group II showed the lowest values among the all experimental groups. While the group III and IV showed insignificance differences as compared with group Ia. On the other hand, group II showed the lowest values of albumin, $\mathrm{Ca}^{+2}$ and 25-hydroxyvitamin D among all the experimental groups followed by group Ib. While, groups III and IV showed insignificance differences as compared with group Ia.

\section{Assessment of the gastrocnemius muscle parameters}

In the resting state, muscle $\mathrm{TNF}-\alpha$ and $\mathrm{MDA}$ levels showed a significant increase and CK and glycogen

Table 4. Mechanical and biochemical parameters of the right (stimulated) and left (resting) gastrocnemius muscles in the different experimental groups.

Data are expressed as mean \pm S.E.M. of 8 rats per group. (Rest.: left resting, Stim.: right stimulated) a: significantly different from the resting limb, b: significantly different from the corresponding limb of the control group, c: significantly different from the corresponding limb of group $\mathrm{lb}$, d: significantly different from the corresponding limb of group II, e: significantly different from the corresponding limb of group III, $P \leq 0.05$. MDA: malondialdehyde; TNF-a: tumor necrosis factor $a$; CK: creatine kinase.

\begin{tabular}{|c|c|c|c|c|c|c|c|c|c|c|c|}
\hline \multirow{2}{*}{\multicolumn{2}{|c|}{$\begin{array}{l}\text { Groups } \\
\text { Parameters }\end{array}$}} & \multicolumn{2}{|c|}{ Group la } & \multicolumn{2}{|c|}{ Group Ib } & \multicolumn{2}{|l|}{ Group II } & \multicolumn{2}{|c|}{ Group III } & \multicolumn{2}{|c|}{ Group IV } \\
\hline & & $\begin{array}{l}\text { Rest. } \\
\text { muscle }\end{array}$ & $\begin{array}{l}\text { Stim. } \\
\text { muscle }\end{array}$ & $\begin{array}{l}\text { Rest. } \\
\text { muscle }\end{array}$ & $\begin{array}{l}\text { Stim. } \\
\text { muscle }\end{array}$ & $\begin{array}{l}\text { Rest. } \\
\text { muscle }\end{array}$ & $\begin{array}{l}\text { Stim. } \\
\text { muscle }\end{array}$ & $\begin{array}{l}\text { Rest. } \\
\text { muscle }\end{array}$ & $\begin{array}{l}\text { Stim. } \\
\text { muscle }\end{array}$ & $\begin{array}{l}\text { Rest. } \\
\text { muscle }\end{array}$ & $\begin{array}{l}\text { Stim. } \\
\text { muscle }\end{array}$ \\
\hline \multicolumn{2}{|c|}{ Force (gm tension) } & & $\begin{array}{l}58.63 \pm \\
1.97\end{array}$ & & $\begin{array}{l}15.75 \pm \\
1.24^{\mathrm{b}}\end{array}$ & & $\begin{array}{l}7.13 \pm \\
1.1^{\mathrm{bc}}\end{array}$ & & $\begin{array}{l}30 \pm \\
1.30^{\mathrm{bcd}}\end{array}$ & & $\begin{array}{l}60 \pm \\
1.73^{\text {cde }}\end{array}$ \\
\hline \multicolumn{2}{|c|}{$\begin{array}{l}\text { Duration in seconds } \\
\text { (till } 50 \% \text { fatigue) }\end{array}$} & & $\begin{array}{l}12.13 \pm \\
1.16\end{array}$ & & $\begin{array}{l}6.25 \pm \\
0.75^{b}\end{array}$ & & $4 \pm 0.46^{b}$ & & \multicolumn{2}{|l|}{$\begin{array}{l}8 \pm \\
0.80^{\mathrm{bd}}\end{array}$} & $\begin{array}{l}15.88 \pm \\
1.16^{\text {bcde }}\end{array}$ \\
\hline \multirow{4}{*}{ 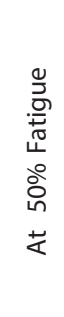 } & $\begin{array}{l}\text { TNF-a (Pg/ } \\
\text { mg) }\end{array}$ & $\begin{array}{l}20.2 \pm \\
0.7\end{array}$ & $\begin{array}{l}25.7 \pm \\
0.9^{a}\end{array}$ & $\begin{array}{l}38.6 \pm \\
1.3^{b}\end{array}$ & $\begin{array}{l}44.4 \pm \\
1.1^{\mathrm{ab}}\end{array}$ & $\begin{array}{l}45.1 \pm \\
1.2^{\mathrm{bc}}\end{array}$ & $\begin{array}{l}51.2 \pm \\
1.3 \mathrm{abc}\end{array}$ & $\begin{array}{l}22.6 \pm \\
1.1^{c d}\end{array}$ & $\begin{array}{l}27.9 \pm \\
0.8^{\text {acd }}\end{array}$ & $\begin{array}{l}18.6 \pm \\
0.9 \text { cde }\end{array}$ & $\begin{array}{l}21.8 \pm \\
0.7 \text { abcde }\end{array}$ \\
\hline & $\begin{array}{l}\text { MDA ( } \mu \mathrm{mol} / \\
\mathrm{gm})\end{array}$ & $\begin{array}{l}11.7 \pm \\
0.8\end{array}$ & $\begin{array}{l}23.6 \pm \\
1.2^{\mathrm{a}}\end{array}$ & $\begin{array}{l}19.7 \pm \\
0.6^{b}\end{array}$ & $\begin{array}{l}44.6 \pm \\
1.6^{\mathrm{ab}}\end{array}$ & $\begin{array}{l}22.7 \pm \\
0.4^{\text {bc }}\end{array}$ & $\begin{array}{l}49.9 \pm \\
1.3 \mathrm{abc}\end{array}$ & $\begin{array}{l}13.2 \pm \\
0.5 \mathrm{~cd}\end{array}$ & $\begin{array}{l}26.1 \pm \\
1.1 \text { acd }\end{array}$ & $\begin{array}{l}11.2 \pm \\
0.5^{\text {cde }}\end{array}$ & $\begin{array}{l}18.3 \pm \\
1.1 \text { abcde }\end{array}$ \\
\hline & CK (U/gm) & $\begin{array}{l}34.5 \pm \\
1.4\end{array}$ & $\begin{array}{l}51.3 \pm \\
1.5^{a}\end{array}$ & $\begin{array}{l}17.4 \pm \\
0.7^{b}\end{array}$ & $\begin{array}{l}22.1 \pm \\
0.8^{a b}\end{array}$ & $\begin{array}{l}14.7 \pm \\
0.9^{\mathrm{bc}}\end{array}$ & $\begin{array}{l}18.4 \pm \\
1.2^{\mathrm{abc}}\end{array}$ & $\begin{array}{l}31.5 \pm \\
1.2^{\mathrm{cd}}\end{array}$ & $\begin{array}{l}45.5 \pm \\
1.7^{\mathrm{abcd}}\end{array}$ & $\begin{array}{l}38 \pm \\
1.3^{\text {cde }}\end{array}$ & $\begin{array}{l}59.2 \pm \\
1.4^{\text {abcde }}\end{array}$ \\
\hline & $\begin{array}{l}\text { Glycogen } \\
\text { (mg/gm) }\end{array}$ & $\begin{array}{c}4.3 \pm \\
0.1\end{array}$ & $\begin{array}{l}3.4 \pm \\
0.2^{\mathrm{a}}\end{array}$ & $\begin{array}{l}3.1 \pm \\
0.1^{b}\end{array}$ & $\begin{array}{l}2.09 \pm \\
0.1 \mathrm{ab}\end{array}$ & $\begin{array}{l}2.5 \pm \\
0.1^{b c}\end{array}$ & $\begin{array}{l}1.7 \pm \\
0.09 \mathrm{abc}\end{array}$ & $\begin{array}{l}4.0 \pm \\
0.2^{\mathrm{cd}}\end{array}$ & $\begin{array}{l}3.3 \pm \\
0.1 \mathrm{acd}\end{array}$ & $\begin{array}{l}4.7 \pm \\
0.2^{\text {cde }}\end{array}$ & $\begin{array}{l}4.1 \pm \\
0.2^{\text {abcde }}\end{array}$ \\
\hline
\end{tabular}



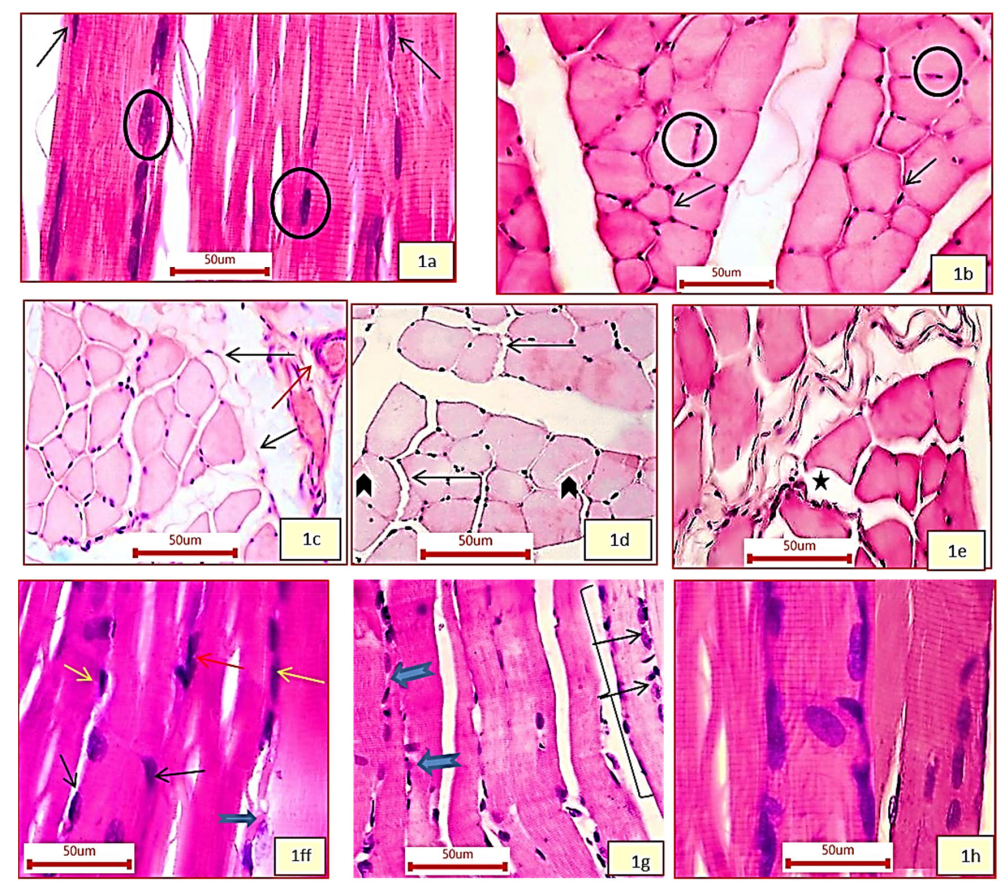

Figure 1. Photo-micrographic plates of muscles.

1a, 1b) Control group, showing L.S (1a) and T.S (1b) of muscle fibers. Polygonal muscle fibers exhibiting various diameters, mosaic distribution, peripheral nuclei (circles) and satellite cells (arrows). 1c) Group lb, showing small aggregates of adipocytes between muscle fibers (black arrows), close to blood vessels (red arrows). 1d-1f) SG group, showing 1d) enlarged, split (arrows) and fragmented faintly stained (arrowheads) fibers; 1e) increased connective tissue density and prominent fibroblasts (asterisks); 1f) myofibers with vesicular linearly arranged nuclei surrounded by satellite cells (black \& yellow arrows), other fibers showing rounded, central (arrowhead) or irregular clumped nuclei (red arrow), and inflammatory cells infiltration (tailed arrow). 19, 1h) Post SG treated groups (III and IV) showing some fibers with multiple peripheral oval nuclei (tailed arrows), regenerating fibers (brace) small size basophilic with large nuclei (black arrows). Notice that in group IV (1h) muscle fibers appeared more or less normal with distinct striation and peripheral nuclei. H\&E staining, $\mathrm{x} 40$ magnification.

showed a significant decrease in group II when compared to group Ia. However, groups III and IV showed insignificant changes (Table 4).

In the stimulated muscle, the parameters significantly changed as compared to its corresponding left resting muscle. SG group (II) showed a significant increase in $\mathrm{TNF}-\alpha$ and lipid peroxides levels and a significant decrease in $\mathrm{CK}$ and glycogen levels. The profile remained the same in post SG treated groups.

Both the resting and the stimulated muscle showed a significant decrease in IGF-1 expression in groups II and $\mathrm{Ib}$ and a significant increase in groups III and IV when compared to group Ia (Fig. 8).

\section{Histological and Immunohistochemical assessment}

H\&E sections:

In the control group (groups Ia, Ib), "L.S" and "T.S" showed the normal histological appearance of skeletal muscles (Fig. 1a and 1b). Intramuscular fat, either scattered or as small aggregation, was observed between muscle fibers in group Ib. Occasionally, it was seen in association with blood vessels (Fig. 1c).

In the SG group (group II), most of the muscle fibers showed normal appearance but some were hypertrophied (Fig. 1d), others atrophied with increased connective tissue density and fibroblasts (Fig. 1e). Occasionally, fibers were clumped with inflammatory cell infiltration (Figure 1f).

In group III, regenerating fibers with distinct transverse striations and multiple peripheral nuclei were observed (Fig. 1g).

In group IV, fibers appeared normal with peripheral nuclei. Linear central nuclei and widening of the endomysium were only seen in few muscle fibers. Fibroblast cell activation, leading to increased synthesis of extracellular matrix and fibers was clearly observed (Fig. 1h).

\section{Histochemical assessment}

Succinic dehydrogenase (SDH): Group Ia was mostly formed by moderately stained type IIA fibers (intermediate fibers), followed by weakly stained type IIB fibers (large fibers) and type I fibers (small and heavily stained fibers) which were occasionally observed (Fig. 2a). In group Ib, fast type IIB fibers were predominant (Fig. 2b). However, group II showed selective atrophy of type II fibers with loss of the staining, while type I fibers were not affected (Fig. 2c). In groups III \& IV, muscle fibers consisted of a large population of oxidative fibers (type IIA and type I) and the lowest population of type IIB fibers (Fig. 2d and 2e).

Glees histochemical staining for nerve fibers: Group Ia showed intact nerves with hen leg appearance of myoneural junctions (Fig. 3a). In group Ib, nerve fibers appeared thinner (Fig. 3a). In group II, nerve fibers showed breakup and thinning (Fig. 3c, 3d). In group III, myelin sheaths and axons of regenerating nerves were significantly increased along the repaired zone (Fig. 3e).

Acetylcholine esterase (AChE) activity: AChE staining was observed in the neuro-muscular junctions (NMJ). In the control group Ia, the NMJs were visible as intensely stained oval, round or elliptical structures, compact and distributed along the border of the muscle fibers (Fig. 4a). In Ib and II group, they were lightly stained, smaller in size and less compact when compared to group Ia but more pronounced (Fig. 4b, c). In group III, the NMJs ap- 


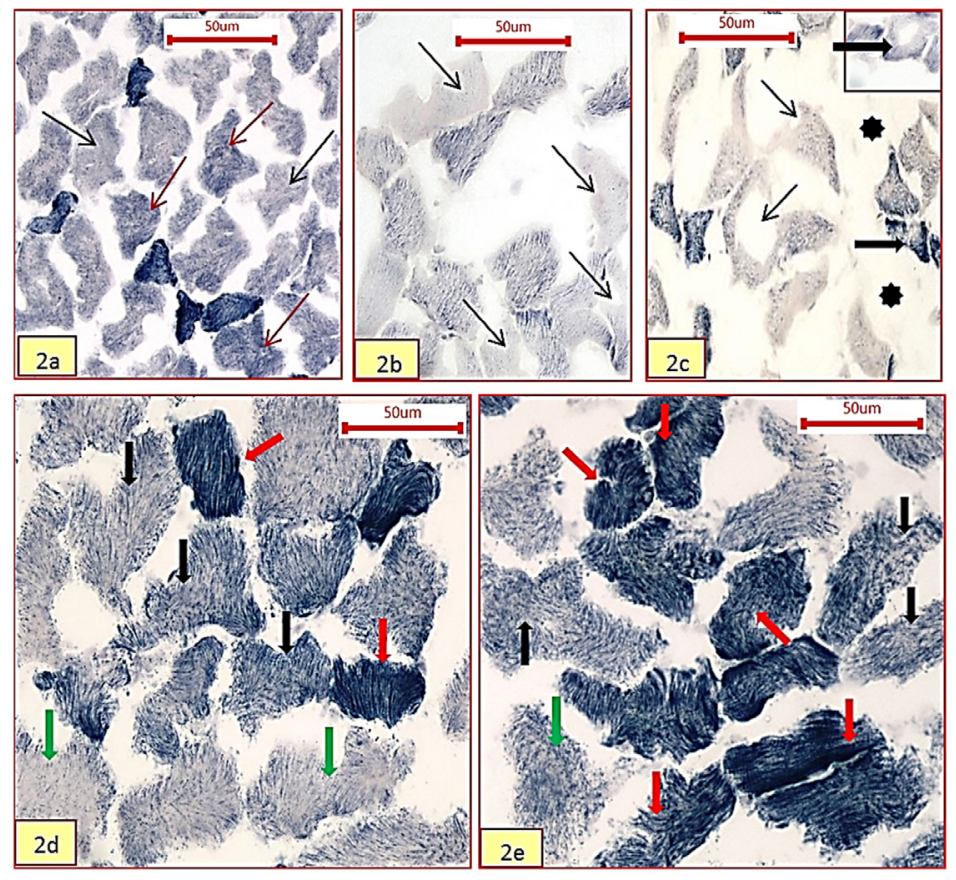

Figure 2. Succinic dehydrogenase enzyme (SDH) activity in the muscle.

2a) Control group la with type IIA fibers (brown arrows) being the most abundant and the pale IIB type (black arrows) the least abundant. 2b) Group Ib with type IIB fibers being predominant (arrows). 2c) Group II showing selective atrophy of type II fibers with central and eccentric loss of staining (arrows) and loss of staining (asterisks). Type I fibers show eccentric loss of staining (thick arrows). 2d, 2e) Post SG treated groups III and IV showing hypertrophied fibers - mostly oxidative fibers type IIA (black arrows) and type I (red arrows) with few type IIB pale fibers (green arrow). Notice that group IV (2e) showed abundant type I dark fibers. SDH staining, x400 magnification.

peared the same as that of the control group Ia while in group IV they appeared more compact (Fig. 4d, e).

Masson trichrome staining of collagen: Collagen fibers were stained intensitylyn group Ib (Fig. 5a) and in the muscular tissue of group II. Collagen was approximately twofold greater in the interstitial space between fibers in the operated groups compared to the group Ia (Fig. 5b, c and d). The amount of intramuscular collagen was apparently maintained in group IV compared to the remaining groups. Groups III and IV showed fibroblast cells activation, leading to increased synthesis of collagens (Fig. 5e and 5f).

Myogenin expression: Group Ia showed an absence of myogenin expression while group $\mathrm{Ib}$ showed weak expression (Fig. 6a, b, c). The operated group II exhibited occasional expression in specialized myogenic cells in between the polyhedral muscle fibers (Fig. 6d). However, groups III and IV showed a high expression (Fig. 6e).

TGF- $\beta 1$ expression: TGF- $\beta 1$ was detected in the control groups (Ia \& Ib), around blood vessels in the connective tissues and fibroblasts (Fig. 7a, b). Group II showed higher TGF- $\beta 1$ expression (Fig. 7c, d). In groups III \& IV lower expression was observed (Fig. 7e and 7f).

\section{Morphometric analysis using the light microscope}

Mean number of myofibers (MNF): There was an insignificant decrease in MNF in group Ib and group II compared to that of group Ia. There was an insignificant increase in the MNF in nutrition-supplemented groups III \& IV and the increase was slightly higher in group IV as compared to the group II (Table 5).

Mean number of myogenin immunopositive cells (Myo. CN): The mean number of myogenin positive cells in group Ia was negligible. Group II showed a significant increase compared to group Ia. Further increase was seen in groups III and IV with the highest significance in group IV (Table 5).

Volume density (Vv.) of muscle fibers (Vv. of different types of muscle fibers) and $\mathrm{Vv}$. col for

Table 5. The mean number of myofibers, myogenin immune-positive cells and the volume density of type I, IIA, and IIB muscle fibers and of collagen fibers of the gastrocnemius muscle in the different experimental groups.

Data are expressed as mean \pm S.E.M. of 8 rats per group. a: significantly different from group la, b: significantly different from group lb, c: significantly different from group II, d: significantly different from group III, $P \leq 0.05$. MNF: mean number of myofibers; Myo. CN: myogenin immune-positive cells; Vv: volume density.

\begin{tabular}{|c|c|c|c|c|c|c|}
\hline \multirow{2}{*}{$\begin{array}{l}\text { Parameters } \\
\text { Groups }\end{array}$} & \multirow{2}{*}{ MNF } & \multirow{2}{*}{ Myo. CN } & \multicolumn{4}{|l|}{ Vvs } \\
\hline & & & type I fiber\% & type IIA fiber\% & type IIB fiber\% & Vv col \% \\
\hline Group la & $98 \pm 2.09$ & $0.01 \pm 0.09$ & $5.68 \pm 0.22$ & $20.09 \pm 0.61$ & $70.23 \pm 0.51$ & $5.89 \pm 0.58$ \\
\hline Group lb & $96.77 \pm 2.01$ & $0.5 \pm 0.05^{a}$ & $5.02 \pm 0.41$ & $18.00 \pm 0.97$ & $69.46 \pm 0.46$ & $6.65 \pm 0.70$ \\
\hline Group II & $96.01 \pm 3.08$ & $0.5 \pm 0.03^{a}$ & $4.64 \pm 0.1^{\mathrm{a}}$ & $15.15 \pm 0.91^{a}$ & $68.07 \pm 0.62$ & $10.32 \pm 0.16^{\mathrm{ab}}$ \\
\hline Group III & $100 \pm 2.11$ & $6.32 \pm 0.4^{\mathrm{abc}}$ & $6.29 \pm 0.23 \mathrm{bc}$ & $29.64 \pm 0.55^{\mathrm{abc}}$ & $55.45 \pm 0.78 \mathrm{abc}$ & $9.32 \pm 0.36^{a b c}$ \\
\hline Group IV & $102.13 \pm 1.12$ & $8.91 \pm 0.5^{\mathrm{abcd}}$ & $6.50 \pm 0.31 \mathrm{bc}$ & $35.58 \pm 0.76^{\mathrm{abcd}}$ & $49.88 \pm 0.19 \mathrm{abcd}$ & $9.67 \pm 0.06^{\mathrm{abc}}$ \\
\hline
\end{tabular}



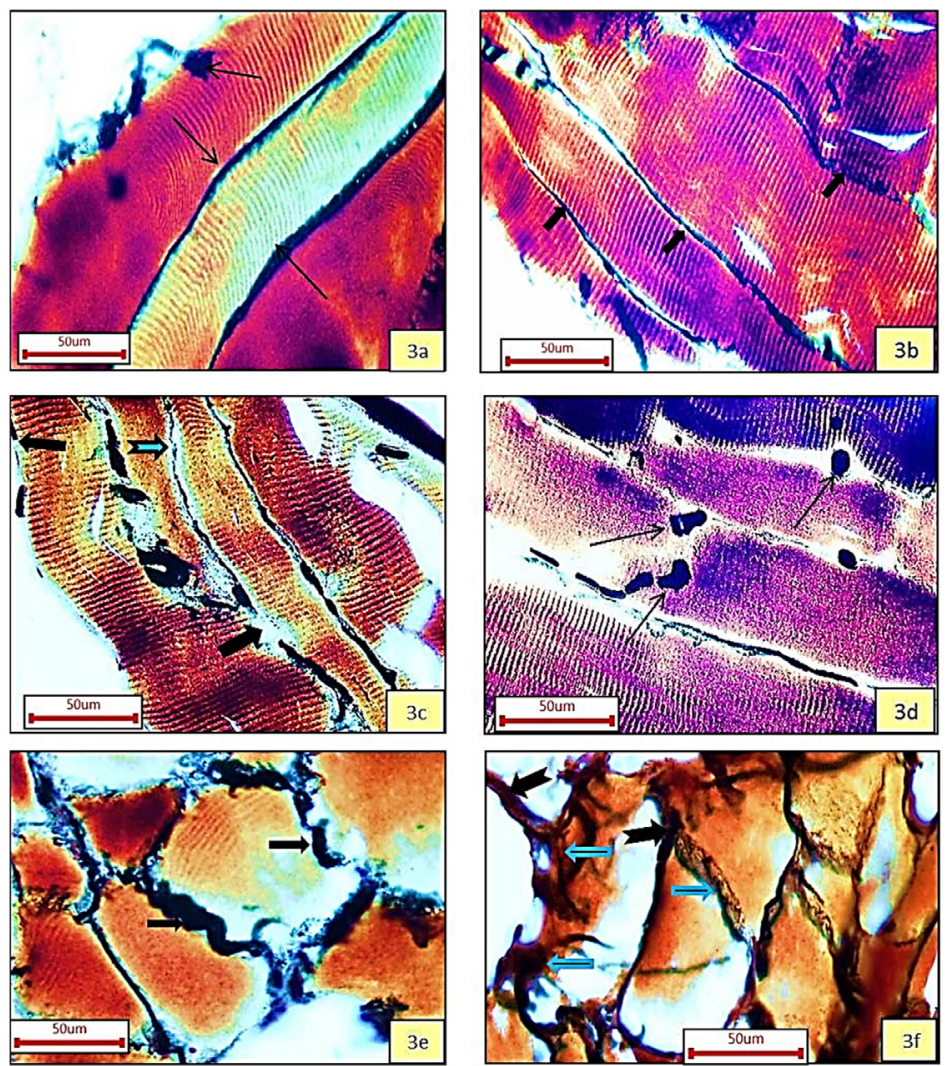

Figure 3. Glees staining for nerve fibers.

3a) The control group la showing intact nerve fibers with a continuous uniform impregnation of silver stain with hen leg appearance of nerve terminals on the surface of the muscle fibers (arrows). 3b) Group 1b with thinner nerve fibers (yellow arrows) and shrinkage of the nerve terminals (black arrow). 3c) SG group II with neurodegenerative changes visible as interrupted nerve fibers (yellow arrows), ghosts (tailed arrow), silver droplets around the degenerated nerves (3d, red arrows). $3 e$, f) Thick myelin sheath in groups III (3e) and IV (3f) (arrows). Group IV showed extensive nerve terminal branching on the surface of muscle fibers (tailed arrow). Glees histochemical staining, x400 magnification.
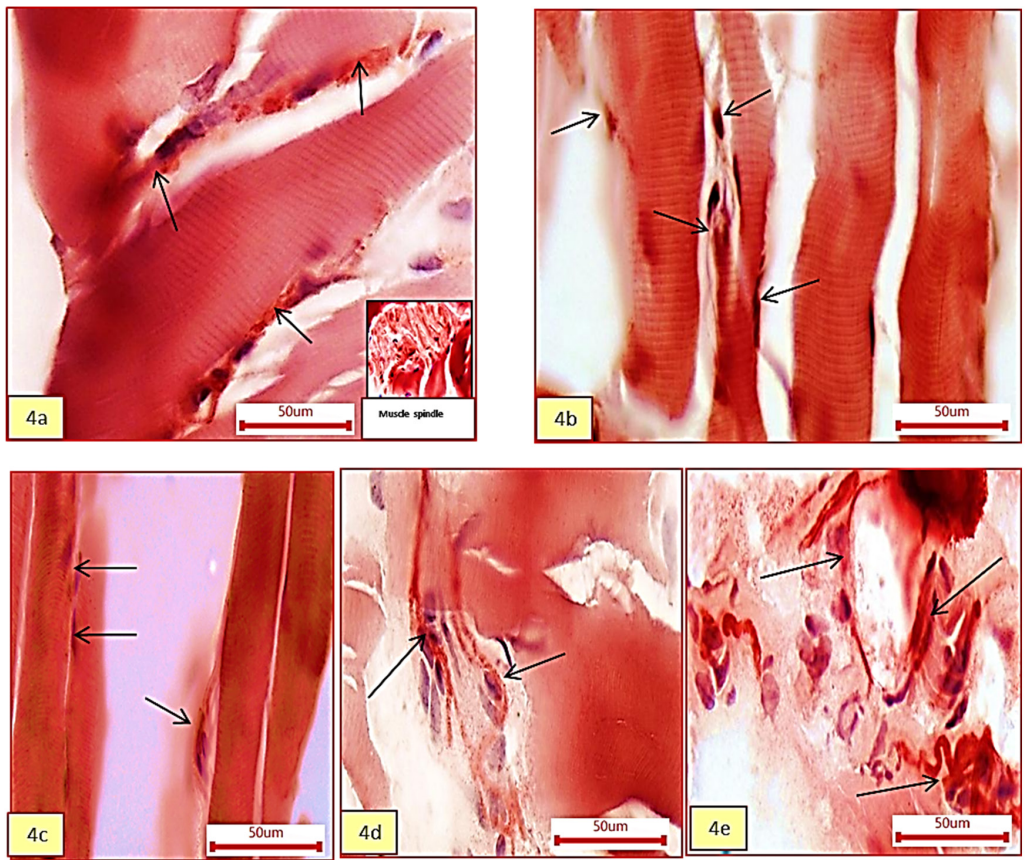

Figure 4. Neuromuscular junctions (NMJ) of the muscle.

4a) Control group la showing brown, oval, round or elliptical compact NMJs, distributed along the border of the muscle fibers (arrows). 4b) Group Ib showing lightly stained NMJs. 4c) SG group II exhibiting smaller and less compact NMJs composed of numerous spot-like contacts on the muscle surface (arrows). 4d) Group III showing NMJs' appearance more or less the same as that of group la. 4e) Group IV with compact NMJs (arrows). Acetylcholine esterase histochemical staining, x400 magnification. 

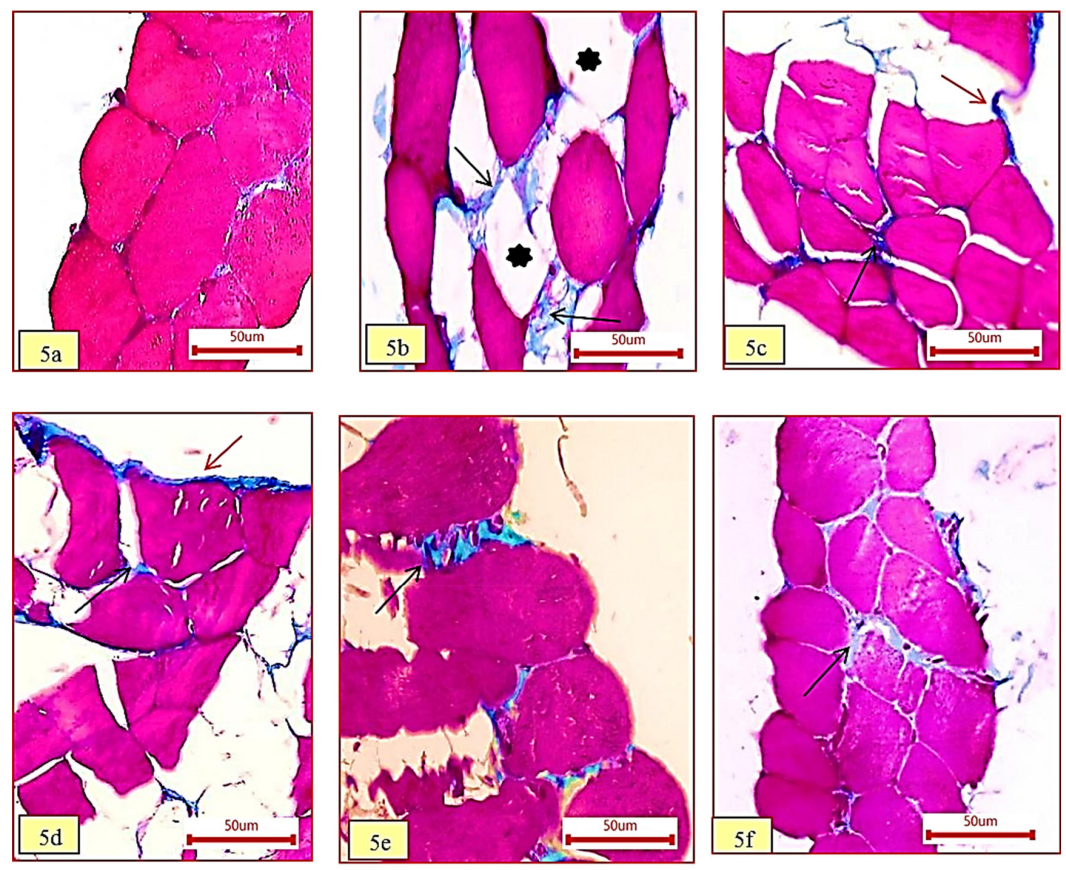

Figure 5. Masson trichrome collagen staining. Increased collagen amount between the accumulated intra-muscular fat cells (asterisks) in group $\mathrm{lb}(5 \mathrm{~b})$ by comparison to group la (5a).

$\mathbf{5 c}$, d) SG group exhibiting prominent deposition of collagen in endomysium and perimysium (black \& red arrows, respectively). 5e, f) Post SG treated groups III and IV showing preservation of the collagen contents. Masson trichrome staining, x400 magnification.
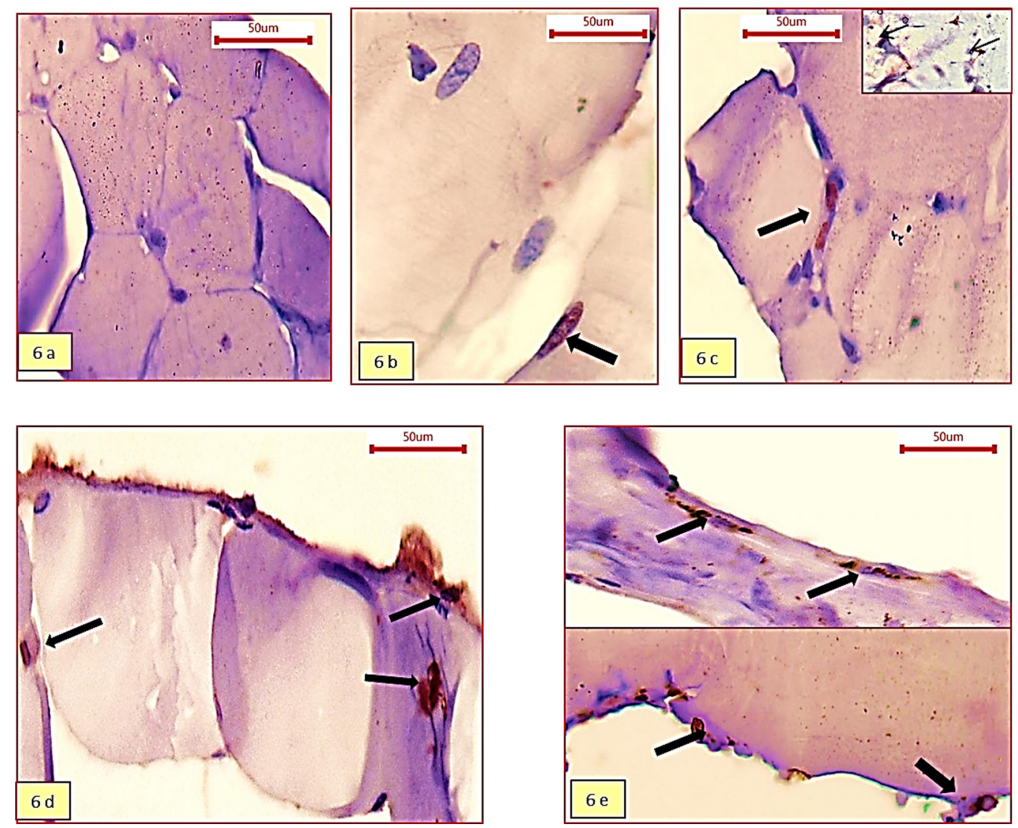

Figure 6. Immunostaining of myogenin.

6a, Control group la showing no immunoreactivity. 6b) Group lb showing weak immunoreactivity (arrow). 6c) SG group II showing nuclear immunoreactivity in myogenic cells in-between the polyhedral muscle fibers (arrow). 6d) Group III showing many immunoreactive myogenic cells. 6e) Group IV showing marked increase in myogenin immunoreactivity (arrows). Myogenin immunostaining, x1000 magnification.

collagen fibers: Group Ia showed predominance of type IIB fibers, followed by type IIA and type I. Groups Ib and II showed insignificant decrease in $\mathrm{Vv}$. of type IIB fibers. On the other hand, groups III and IV showed a significant decrease. In the latter groups, there was a significant muscle remodeling characterized by an increase in the volume density of oxidative fibers (type I and type IIA). The increase was significant for type I and highly significant for IIA fibers. There were nearly identical values of volume density of collagen fibers "Vv. col" in group Ib and group Ia, but in groups III and IV, there was an insignificant increase compared to group Ib. On the other hand, 

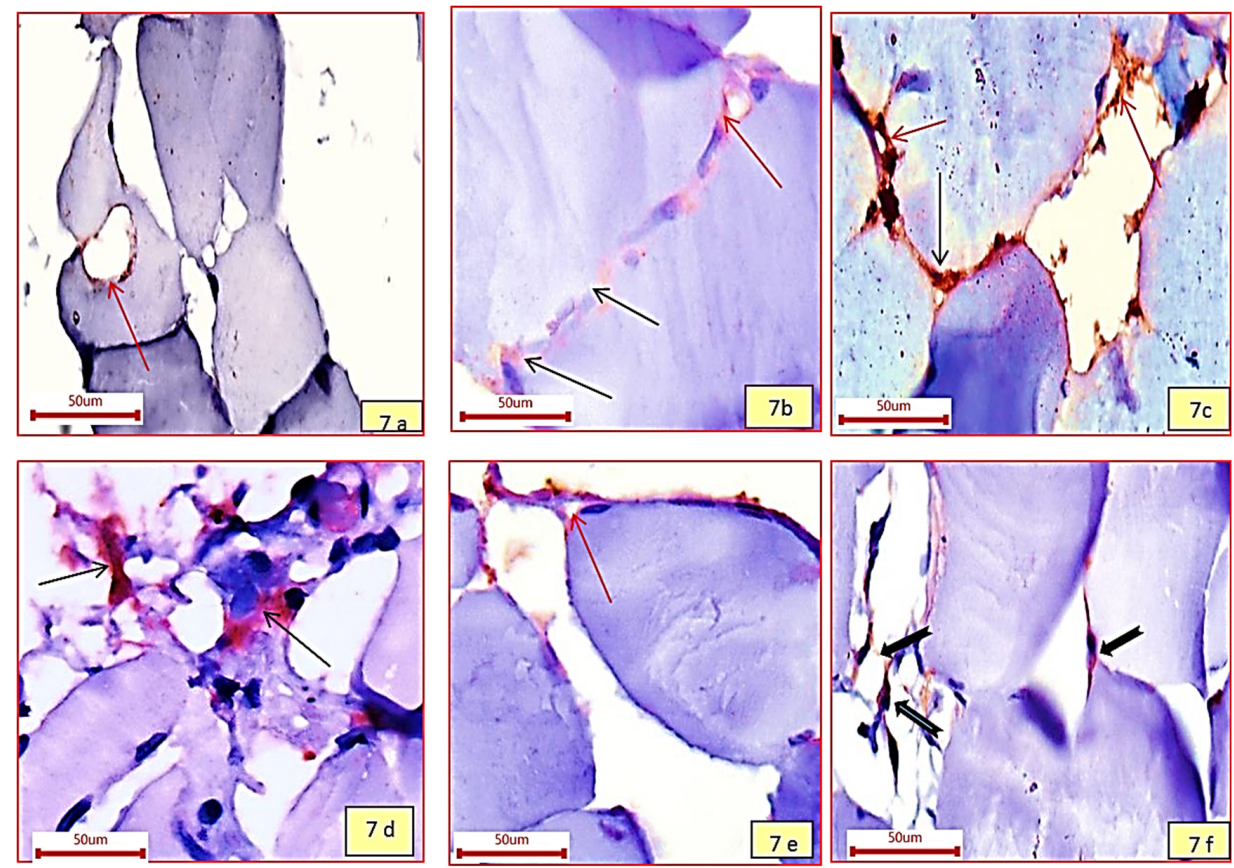

Figure 7. Immunostaining of TGF- $\beta$.

7a) Control group la showing TGF- $\beta$ expression around blood vessels. 7b) Group Ib showing weak expression in the endomysium (black arrows) and near the blood vessels (red arrows). 7c, d) Group II showing upregulation of TGF- $\beta$ expression around the blood vessels (red arrows) primarily in the endomysium and in the connective tissue (black arrows). 7e, f) Post SG treated groups III and IV showing downregulation of TGF- $\beta$ in the endomysium (red arrow) and in the fibroblasts (tailed arrow). TGF- $\beta$ immunostaining, x1000 magnification.

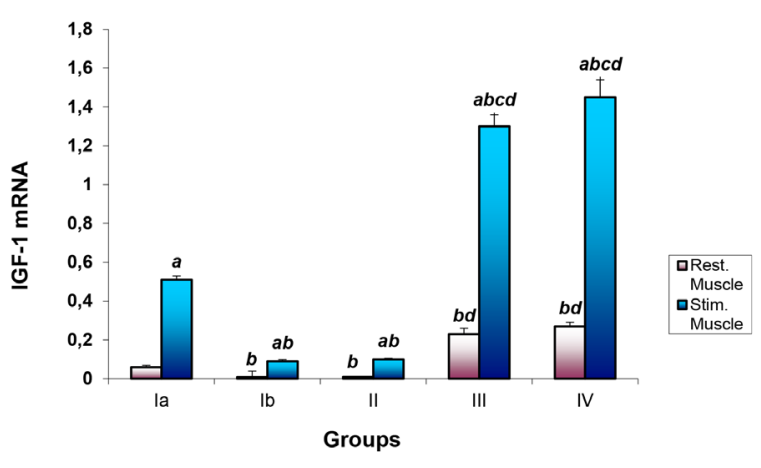

Figure 8. Quantitative analysis of IGF-1.

Data are expressed as mean \pm S.E.M. of 6 rats per group (Rest.: left resting, Stim.: right stimulated). a: significantly different from group la, b: significantly different from group lb, c: significantly different from group II, d: significantly different from group III. $P \leq 0.05$. IGF-1: Insulin growth factor-1.

Table 6. Cross-sectional area of myocytes $\left(\mu \mathrm{m}^{2}\right)$ (CSA) of the gastrocnemius muscle according to the fiber types.

Data are expressed as mean \pm S.E.M. of 8 rats per group. a: significantly different from group la, b: significantly different from group $\mathrm{lb}$, c: significantly different from group II, d: significantly different from group III, $P \leq 0.05$

\begin{tabular}{llll}
\hline $\begin{array}{l}\text { Parameters } \\
\text { Groups }\end{array}$ & Type I $\left(\mu \mathrm{m}^{2}\right)$ & Type IIA $\left(\mu \mathrm{m}^{2}\right)$ & Type IIB $\left(\mu \mathrm{m}^{2}\right)$ \\
\hline Group Ia & $2202.40 \pm 31.87$ & $3089.62 \pm 61.45$ & $4136.22 \pm 57.77$ \\
\hline Group Ib & $2146.49 \pm 35.07$ & $2768.20 \pm 67.85^{\mathrm{a}}$ & $4090.87 \pm 29.33$ \\
\hline Group II & $2079.14 \pm 42.21^{\mathrm{a}}$ & $2329.90 \pm 66.10^{\mathrm{ab}}$ & $3909.01 \pm 25.28^{\mathrm{a}}$ \\
\hline Group III & $2438.92 \pm 50.78^{\mathrm{abc}}$ & $4558.30 \pm 79.43^{\mathrm{abc}}$ & $3265.75 \pm 81.66^{\mathrm{abc}}$ \\
\hline Group IV & $2520.35 \pm 72.50^{\mathrm{abc}}$ & $6086.96 \pm 59.94^{\mathrm{abcd}}$ & $2702.12 \pm 35.48^{\mathrm{abcd}}$ \\
\hline
\end{tabular}

group II showed higher values of "Vv. col" when compared to all other groups (Table 5).

Cross-sectional area of muscle fibers (CSA): In group $\mathrm{Ib}$ and II, type IIB fibers has insignificantly lower area compared to group Ia. Groups III and IV showed a significant decrease in the CSA of type IIB fibers compared to that in the group Ia. Moreover type IIA and type I fibers (oxidative fibers) showed a clear remodeling reflected by a significant increase of the CSA of type I fibers and a highly significant increase of type IIA fibers when compared to group Ia (Table 6).

\section{Right gastrocnemius muscle response}

Group Ib showed a significantly reduced peak force upon electric stimulation associated with shortened time till $50 \%$ decline of peak force indicating accelerated fatigue in comparison to group Ia. On the contrary, group II showed a significantly lowered peak force with an insignificant change of the time till 50\% fatigue as compared to group Ib. Introducing supplementation to $\mathrm{SG}$ rats resulted in a significant increase in the peak force when compared to both $\mathrm{Ib}$ and II group and prolongation of the time till 50\% fatigue compared to group II, but these parameters were still significantly lower compared to group Ia. On the other hand, physical exercise with supplementation introduced in SG rats led to significant improvement of muscle contraction, regarding peak force and the time till $50 \%$ fatigue, as compared to groups Ib, II and III, but in comparison with group Ia, the peak force was not significantly different while the time till $50 \%$ fatigue was significantly increased (Fig. 9 and Table 4). 

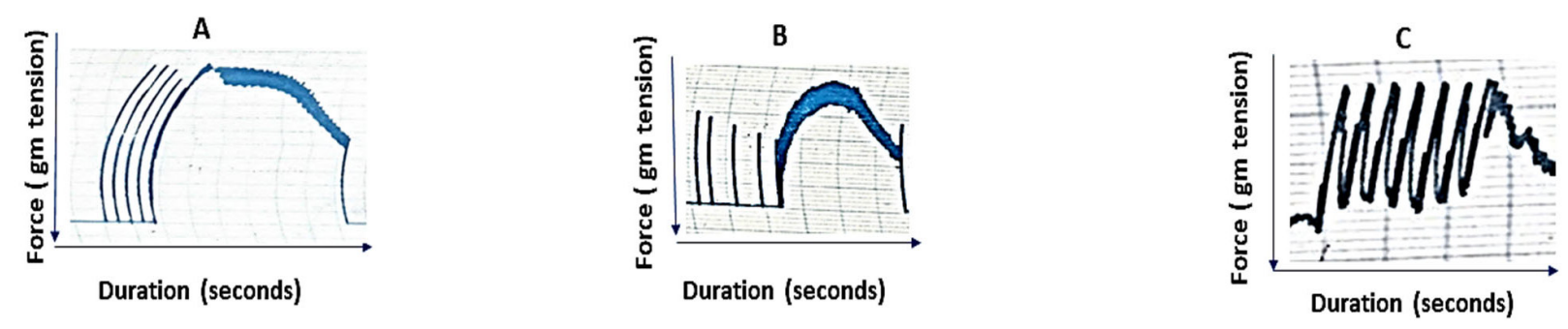

D

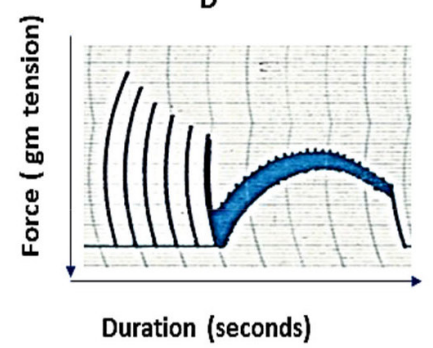

E

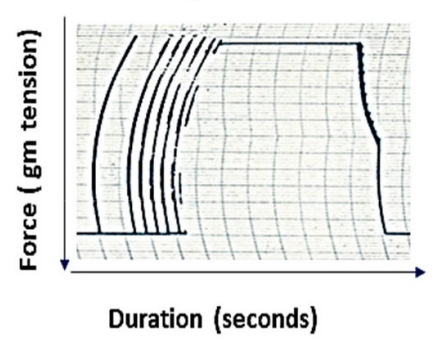

Figure 9. Right gastrocnemius muscle response of the different experimental groups represented by a vertical line (Force, gm tension); one big vertical square $=5 \mathrm{~g}$ tension, and horizontal line (the time (t) till $50 \%$ decline from peak force); one big horizontal square $=2$ seconds duration.

A: group la, B: group Ib, C: group II, D: group III, E: group IV. $P \leq 0.05$.

\section{DISCUSSION}

Obesity is one of the metabolic disorders that affects skeletal muscle function (Tallis et al., 2018). Skeletal muscle is the largest metabolic organ performing carbohydrate and fat oxidation followed by the liver, thus, it is affected by nutritional disorders (Müller et al., 2014). It is responsible for $85 \%$ of insulin-mediated glucose clearance and maintaining whole-body glucose homeostasis. Metabolic disorders of the muscle and disruption of mitochondrial activity, fatty acids oxidation, and glycolysis cause failure of glucose homeostasis (Abu-Remaileh et al., 2019).

Gastrocnemius muscle received attention in research because it consists of type I or slow-twitching muscle fibers and type II or fast-twitching muscle fibers (Ibrahim et al., 2016). Furthermore, this study showed that electric stimulation-induced metabolic, molecular and cellular changes in the muscle. Some evidence at the cellular level suggests that electrical stimulation increases reactive oxygen species (ROS) production (Dong et al., 2018). In addition, it can affect the regeneration process as well as the oxidative stress of satellite cells (Di Filippo et al., 2017).

HFD group being the model obese group showed increased BMI, possibly due to the high caloric content of satiety pellets (Lipinski et al., 2017). It showed a disturbed lipid profile and the highest atherogenic index. Obesity is associated with metabolic disorders: »dyslipidemia, atherosclerosis and type II diabetes» as a result of energy impairment and increased caloric intake compared to the calories loss (Orsolic et al., 2019). The hyperinsulinemia and hyperglycemia sparing glucose are attributed to the higher free fatty acid content in the HFD that compete with glucose for mitochondrial oxidation, hence and promoting lipid oxidation; and lipid metabolites interfere with insulin function resulting in the development of insulin resistance (Ibrahim et al., 2017).
Hyperglycemia increases the activity of mitochondrial NADPH oxidase and mitochondrial biogenesis with an excessive generation of ROS as detected by the increase in MDA levels (Hurrle \& Hsu, 2017). Reduction in plasma albumin level could be attributed to the decreased insulin action and the associated chronic inflammation (Chang et al., 2019). Moreover, insulin resistance may account for obesity-related hyper-filtration, glomerulomegaly, and albuminuria (Martinez et al., 2019). The reduction in serum 25-hydroxy vitamin-D and $\mathrm{Ca}^{+2}$ may be caused by vitamin D metabolic disorder associated with obesity including lower dietary intake, reduced cutaneous synthesis or altered metabolism with the subsequent decrease in $\mathrm{Ca}^{+2}$ absorption (Ali et al., 2019).

HFD group showed histopathological changes with a decrease in both volume density and cross-sectional area of all types of muscle fibers. Thus, the muscle becomes metabolically inflexible, probably due to inefficient oxidation of carbohydrates and lipids leading to progressive intracellular deposition of lipid droplets, ATP deficiency, and inflammatory cellular infiltration (Abu-Remaileh et al., 2019) that result in progressive muscle fatigue (Wu \& Ballantyne, 2017). Furthermore, it was reported that long-term HFD leads to excessive accumulation of fat tissue in skeletal muscles and muscle atrophy by activating the atrophy-pathway proteins such as TNF- $\alpha$ (Ferretti et al., 2018). Moreover, the predominance of type IIB fast fibers might account for the inefficient oxidation of the muscle; in line with this, it was reported that obese patients' skeletal muscles exhibit low oxidative capacity by transiting from slow oxidizing muscle fibers to rapidly twitching fibers (Tallis et al., 2018).

The functional impairment of skeletal muscle in the HFD group demonstrated by the reduced force and accelerated fatigue could be attributed to dysfunctional mitochondrial oxidation with subsequent reduction in ATP generation, glycogen storage and creatine kinase (CK) 
activity (Hamrick et al., 2016). CK ensures adequate energy supply for the skeletal muscle upon rest and during activity (Baird et al., 2012). The significantly higher $\mathrm{CK}$ level in the gastrocnemius muscle of the stimulated limb in the control group in this study suggests continuous supply of ATP. However, CK activity can also contribute to muscle fatigue especially under oxidative stress conditions when the breakdown of CK results in excessive accumulation of inorganic phosphate (Pi) (Wan et al., 2017).

Although a number of growth factors have the potential to influence muscle repair, there is strong evidence that insulin-like growth factor-1 (IGF-1) is a powerful enhancer of tissue regeneration and coordinates the regeneration of skeletal muscles by stimulating the muscle satellite cells. The increased expression of IGF-1 in muscle injury accelerates the inflammation as reported by (Tonkin et al., 2015). HFD causes mitochondrial dysfunction that leads to insulin resistance and reduced muscle mass by lowering protein levels of IGF-1 as shown in the present study (Ferretti et al., 2018).

Sleeve gastrectomy (SG) is considered a restrictive measure to reduce oral intake by reducing stomach size (White et al., 2019). It is considered a highly effective treatment of obesity and improvement of the quality of life by sustaining weight loss, reducing comorbid diseases and deaths related to obesity. In the present work, we aimed to study the molecular, cellular and physiological adaptation of the gastrocnemius muscle to SG. SG resulted in a significant decrease in BMI, changes in lipid profile and glucose level as compared to the obese rats. This can be attributed to the reduced intake of food that was also observed in the postoperative groups (Arble et al., 2018).

SG group showed a significant reduction in serum insulin, serum albumin, $\mathrm{Ca}^{+2}$ and 25-hydroxy vitamin$\mathrm{D}$ levels. Insulin levels reduction could be attributed to the hormonal mechanisms as the levels of YY peptide (PYY) and Glucagon-like peptide 1 (GLP-1) secreted by L-cells of the hindgut appeared to increase after SG. The increase in PYY and GLP-1 levels is due to the acceleration of gastric emptying and early contact of the chyme with L-cells (Catoi et al., 2016) compared to all other experimental groups. Albumin, $\mathrm{Ca}^{+2}$ and 25-hydroxy vitamin-D levels reduction could be attributed to the decreased food intake and the physiological effect of the anatomical changes caused by the surgery (Donadelli et al., 2012). Generally, one of the complications of the surgical correction of obesity is under-nutrition, a condition of excessive catabolism that leads to loss of both fat and protein (Sharma et al., 2019).

Physiologically, the SG group showed a reduction in peak force generation indicating a reduction in muscle power, and a shortening of the time till half relaxation indicating fatigue acceleration. Muscle power reduction and easy fatigability could be attributed to: 1) the histopathological changes seen in the muscle fibres including degenerative, inflammatory and fibrotic changes (Saclier et al., 2013); 2) inflammatory cell infiltration into the muscle, especially macrophages (Desgeorges et al., 2019) which could be the source of high TNF- $\alpha$ level noticed in the present study; 3) the molecular and metabolic changes in the muscle as a consequence of malnutrition following SG due to restriction of food intake; 4) metabolic disorders may be greater in type II compared to type I fibers due to the faster rate of degradation of phosphocreatine and anaerobic breakdown of glucose and hence accumulation of lactate and $\mathrm{H}^{+}$(Brzobohatý et al., 2015). They added that the daily food intake re- striction is able to induce fiber loss with a higher share of type IIB muscle fibers.

SG group showed a reduction in glycogen and CK levels due to a decrease in food intake that results in malnutrition, decreased energy sources and acceleration of fatigue. ROS production leads to the oxidation of proteins, fatty or nucleic acids accompanied by a marked decrease in the antioxidant capacity, which ultimately leads to fatigue (Wan et al., 2017). It was also proven in the current study through a significant increase in the MDA.

Muscle growth, development and regeneration occur throughout the life of vertebrates and the processes are characterized by the proliferation of precursor cells, followed by the expression of genes for muscles, and finally the merging of differentiated muscle cells into myotubes (Murphy \& Kardon, 2011). Myogenin is a skeletal muscle-specific gene that encodes a myogenic regulator essential for skeletal muscle formation and repair (Bentzinger et al., 2012). Following muscle injury, satellite cells are activated into muscle precursors, multiply, migrate toward each other and merge into muscle fibers (Zammit, 2017). This process accounts for the increase in the cross-sectional area of muscle fibers and the increase in the mean number of myogenin-positive cells in the SG group.

Moreover, the current study revealed a significant decrease in the expression of IGF-1 mRNA in the skeletal muscle both in the resting state and even upon stimulation in the SG group. IGF-1 concentration is usually affected by multiple factors; apart from genetics and hormones, especially nutrition is considered to be the key factor for IGF-1 production (Ban \& Zhao, 2018). Malnutrition can alter the growth hormone/IGF-1 axis at multiple levels including decreasing its gene expression, accelerating IGF-1 decomposition, and reducing the biological activity of serum IGF-1. Therefore, in the present study, we rejected the concept that the competing processes of cellular proliferation, differentiation and increased protein synthesis required for muscle repair or hypertrophic adaptation in the SG group were regulated by the expression of IGF-1.

SG group showed an upregulation of pro-inflammatory factor TGF- $\beta 1$ which is an important cytokine for extracellular matrix synthesis and fibrosis (Delaney et al., 2017). Thus, the resulting fibrosis could weaken the muscle function, negatively affect muscle regeneration and increase the susceptibility of muscles to re-injury (Mahdy, 2019).

In post-SG treatment, increased protein intake may have impressive effects on appetite, metabolic rate and weight loss (Arentson-Lantz et al., 2015). Moreover, vitamin $\mathrm{D}$ affects the muscular system by stimulating muscle cells proliferation and differentiation (Zadka et al., 2018). Vitamin B complex is involved in many important physiological functions such as carbohydrates and fatty acids metabolism, cell proliferation, and cell membrane permeability (EL-Toweissy et al., 2013). Leucine supplementation is an effective nutritional strategy for increasing muscle mass (Amaral et al., 2015). It improved HGH resistance in malnourished rats by enhancing IGF-1 production, reducing IGF-1 degradation, and facilitating the synthesis of $\mathrm{HGH}$ receptors in the liver (Gao et al., 2015)).

Compiling evidence has shown that selenium (Se) is a trace mineral that is essential to human health (Mistry et al., 2012). It is known for its antioxidant properties responsible for its antiviral and anti-cancer capabilities. Moreover, it is important for normal muscle function. 
Musculoskeletal disorders that appear as muscle pain, fatigue, weakness, and high serum creatine kinase (CK) were reported in patients with selenium deficiency (Bodnar et al., 2016).

Post-SG treated groups (group III and IV) showed marked improvement in biochemical parameters as compared to the obese and SG groups. They showed insignificant differences in all the resting gastrocnemius muscle parameters compared to the $S G$ group. However, group VI showed significantly lower TNF- $\alpha$ and MDA levels and significantly higher CK and glycogen levels in stimulated right gastrocnemius if compared to group Ia and III. This could be explained by the fact that selenium supplementation is important for the body's antioxidant defense mechanism and suppresses the production of interleukins and TNF- $\alpha$ (Dasgupta \& Aly, 2016). It is also important for the improvement of skeletal muscular dystrophy due to the down regulation of myogenin and related cytokines (Bodnar et al., 2016).

Skeletal muscles are a very dynamic tissue, capable of continuous reconfiguration in response to various environmental stimuli as proved by a significant increase in the myogenin-positive cells in post-SG treated groups compared to that of the SG group. There was a correlation between protein availability and satellite cells proliferation, differentiation, and myonuclear accretion. Muscle tubes in muscle fibers and ECM undergo remodeling, which has a major role in transferring strength, maintenance and repair of muscle fibers (Zammit, 2017). Furthermore, there was a significant increase in the IGF-1 mRNA expression in the post SG treated group which could be attributed to selenium supplementation (Alehagen et al., 2017). IGF-1 production in group IV which underwent physical exercise could be attributed to the mechanical activity (Ichinose et al., 2014). TGF- $\beta 1$ localization at sites targeted for regeneration such as in the endomysium fibroblasts around the muscle fibers could be for regulating muscle repair by activating satellite cells, forming connective tissues, as well as regulating the intensity of the immune response. (Delaney et al., 2017).

In post-SG groups, muscle fibers exhibited signs of regeneration that might be attributed to enhanced metabolic activity of protein synthesis to restore the damaged cells (Roman \& Gomes, 2018). In addition, volume density "Vv" of collagen fibers showed a non-significant increase. This might be a consequence of fibroblast cells activation, leading to increased synthesis of ECM and fibers that form a structural network holding myofibers together and providing them with blood and nerve supply.

Therefore, in the post-SG group muscle fibers showed cellular and molecular changes indicating regenerative activity which indeed could improve muscle contractility. This was confirmed by demonstrating that the peak force and the time till 50\% fatigue improved. It could be explained that the NMJ (Neuromuscular junction) in the post-SG groups restored its normal appearance suggesting an improved quality of axons. In addition, the muscle fibers showed apparent hypertrophy that was emphasized in group IV consisting of a large population of oxidative fibers (type IIA and type I) and the lowest population of type IIB fibers. It could be said that nutritional supplementation increased the rate of myofibrillar protein synthesis and the exercise-stimulated rate of muscle protein synthesis to an even greater extent (Trabal et al., 2015).

Interestingly, physical exercise along with nutritional supplementation following SG resulted in improvement in the muscle, probably because the anabolic and muscle pathways are strongly influenced by physical exercises. Regular training improves muscle mass and strength by increasing protein synthesis, the number of fibrous fibers, and the cross-sectional area of the fibers. Exercise increases IGF-1 levels with the subsequent induction of protein synthesis. Moreover, the exercises increase the muscle fiber protein by activating the satellite cells and reduce the fat leakage into the muscles. In addition to stimulating muscle metabolism, exercise prevents protein degradation, and this effect may be mediated by low levels of oxidative stress after training (Gomes et al., 2017). Physical activity improves antioxidant defense and lowers lipid peroxide levels. Therefore, consuming enough high-quality protein with physical activity appears to be a promising strategy to prevent or treat muscle weakness and muscle atrophy (Simioni et al., 2018).

\section{CONCLUSION}

It is evident that malnutrition due to food restriction following SG is a major cause of muscle atrophy with metabolic and functional deterioration. Besides, nutritional supplementation together with physical exercise are necessary to maintain muscle mass and strength, along with synchronistic new muscle fibers innervation by the surviving nerve terminals. Due to the difficulties in performing such a study in humans, the present study conclusions should be reflected in the recommendations for patients after SG surgery.

\section{Limitations}

One of the drawbacks of the present study was the short follow-up of 6 weeks. However, this period is equivalent to 3 years of human life (Brinckerhoff et al., 2013). Another limitation was the smaller groups due to the high complication rate in the post-operative rats.

\section{Acknowledgment}

The authors would like to thank the technicians of the Pharmacology Department, Minia University Faculty of Medicine, Egypt for their support during performing this work.

\section{Declaration of interest:}

The authors declare that there is no conflict of interest that could be perceived as violating the impartiality of the research reported.

\section{Ethical approval}

All applicable international, national, and/or institutional guidelines for the care and use of animals were followed according to the guidelines of the Animal Care and Committee of Faculty of Medicine, Minia University, Minia, Egypt.

\section{Author Contribution Statement}

All authors' contribution to the paper was almost equal including interpretation of the results and writing of the manuscript. First, third, fifth and eighth author contributed to the histopathologic examination.

\section{REFERENCES}

Abu-Remaileh M, Abu-Remaileh M, Akkawi R, Knani I, Udi S, Pacold ME, Tam I, Aqeilan RI (2019) WWOX somatic ablation in skel- 
etal muscles alters glucose metabolism. Mol Metab J 22: 132-140. https://doi.org/10.1016/j.molmet.2019.01.010

Alatawi FS, Faridi UA, Alatawi MS (2018) Effect of treatment with vitamin D plus calcium on oxidative stress in streptozotocininduced diabetic rats. Saudi Pharm J 26: 1208-1213. https://doi. org/10.1016/j.jsps.2018.07.012

Alehagen U, Johansson P, Aaseth J, Alexander J, Brismar K (2017) Increase in insulin-like growth factor 1 (IGF-1) and insulin-like growth factor binding protein 1 after supplementation with selenium and coenzyme Q10. A prospective randomized double-blind placebo-controlled trial among elderly Swedish citizens. PloS One 12: e0178614. https://doi.org/10.1371/journal.pone.0178614

Ali AA-M, Mansour A, Hassanine E-SA-E, Abdel-Razek AH, Mahmoud HAH (2019) Ameliorative role of a combination of chitosan, calcium, vitamins $A$ and $E$ against high fat diets-induced adverse effects in rats. J Basic Appl Zool 80: 11. https://doi. org/10.1186/s41936-019-0081-7

Amaral RB, Martins CEC, Lancha AH Jr, Painelli VS (2015) Can leucine supplementation attenuate muscle atrophy? A literature review. Revista Brasileira de Cineantropometria \& Desempenho Humano. 17: 496506. https://doi.org/10.5007/1980-0037.2015v17n4p496

Arble DM, Evers SS, Bozadjieva N, Schmidt HF, Myronovych A, Lewis A, Toure MH, Seeley RJ (2018) Metabolic comparison of one-anastomosis gastric bypass, single-anastomosis duodenal-switch, Roux-en-Y gastric bypass, and vertical sleeve gastrectomy in rat. Surgery for obesity and related diseases. Official J Am Soc Bariatric Surgery 14: 1857-1867. https://doi.org/10.1016/j.soard.2018.08.019

Arentson-Lantz E, Clairmont S, Paddon-Jones D, Tremblay A, Elango R (2015) Protein: a nutrient in focus. Appl Physiol Nutri Metabol 40: 755-761. https://doi.org/10.1139/apnm-2014-0530

Baird MF, Graham SM, Baker JS, Bickerstaff G F (2012) Creatinekinase- and exercise-related muscle damage implications for muscle performance and recovery. J Nutri Metabol 13: 960363. https://doi. org/10.1155/2012/960363

Ban B, Zhao Q (2018) Nutritional regulation of growth hormone/ insulin-like growth factor-1 axis. Nutri Food Sci Int J 7: 154-156. https://doi.org/10.19081/NFSIJ.2018.07.555725

Bancroft JD, Gamble D (2008) Theory and Practice of Histological Techniques. Churchill Livingstone, London

Bentzinger CF, Wang YX, Rudnicki MA (2012) Building muscle: molecular regulation of myogenesis. Cold Spring Harb Perspect Biol 4: a008342 https://doi.org/10.1101/cshperspect.a008342

Bodnar D., Ruzsnavszky O, Olah T, Dienes B, Balatoni I, Ungvari E, Benko I, Babko B, Prokisch J, Csernoch L, Szentesi P (2016) Dietary selenium augments sarcoplasmic calcium release and mechanical performance in mice. Nutri Metabol 13: 76. DOI: https://doi. org/10.1186/s12986-016-0134-6

Brinckerhoff T Z, Bondada S, Lewis C E, French S, DeUgarte D A (2013) Metabolic effects of sleeve gastrectomy in female rat model of diet-induced obesity. Surgery for obesity and related diseases. $O f$ ficial J Am Soc Bariatric Surgery 9: 108-112. https://doi.org/10.1016/j. soard.2011.09.025

Brzobohatý L., Stupka R, Čítek J., Sprysl M, Okrouhla M, Vehovsky K (2015) The influence of controlled nutrition intensity on the muscle fiber characteristics in fattening pigs. J Central Eur Agric 16: 92-99. https://doi.org/10.5513/JCEA01/16.1.1546

Campos K E d, Volpato G T, Calderon I M P, Rudge M V C, Damasceno D C (2008) Effect of obesity on rat reproduction and on the development of their adult offspring. Braz J Med Biol Res 41: 122125. https://doi.org/10.1590/s0100-879x2008005000001

Catoi A F, Parvu A, Mironiuc A, Galea R F, Muressan A, Bidian C, Pop I (2016) Effects of sleeve gastrectomy on insulin resistance. Clujul Med 89: 267-272. https://doi.org/10.15386/cjmed-576

Chang DC, Xu X, Ferrante AWF, Jr, Krakoff J (2019) Reduced plasma albumin predicts type 2 diabetes and is associated with greater adipose tissue macrophage content and activation. Diab Metabol Syndrome 11: 14. https://doi.org/10.1186/s13098-019-0409-y

Chinopoulos C. (2013) Which way does the citric acid cycle turn during hypoxia? The critical role of alpha-ketoglutarate dehydrogenase complex. J Neurosci Res 91: 1030-1043. https://doi.org/10.1002/ jnr.23196

Crozier SJ, Kimball SR, Emmert SW, Anthony JC, Jefferson LS (2005) Oral leucine administration stimulates protein synthesis in rat skeletal muscle. I Nutri 135: 376-382. https://doi.org/10.1093/ jn/135.3.376

Dasgupta S, Aly AM (2016) Dilated cardiomyopathy induced by chronic starvation and selenium deficiency. Case Reports Pediatrics 2016: 8305895 https://doi.org/10.1155/2016/8305895

Davidson T L, Monnot A, Neal AU, Martin A A, Horton J J, Zheng W (2012) The effects of a high-energy diet on hippocampal-dependent discrimination performance and blood-brain barrier integrity differ for diet-induced obese and diet-resistant rats. Physiol Beh J 107: 26-33 https://doi.org/10.1016/j.physbeh.2012.05.015

Delaney K, Kasprzycka P, Ciemerych MA, Zimowska M (2017) The role of TGF-beta1 during skeletal muscle regeneration. Cell Biol Int J 41: 706-715. https://doi.org/10.1002/cbin.10725
Desgeorges T, Caratti G, Mounier R, Tuckermann J, Chazaud B (2019) Glucocorticoids shape macrophage phenotype for tissue repair. Front Immunol J 10: 1591-1591. https://doi.org/10.3389/fimmu.2019.0159

Di Filippo ES, Mancinelli R, Marrone M, Doria C, Verratti V, Toniolo L, Dantas J L, Fulle S, Pietrangelo T (2017) Neuromuscular electrical stimulation improves skeletal muscle regeneration through satellite cell fusion with myofibers in healthy elderly subjects. I Appl Physiol 123: 501-512. https://doi.org/10.1152/japplphysiol.00855.2016

Donadelli SP, Junqueira-Franco MV, de Mattos Donadelli C A, Salgado W, Ceneviva R, Marchini J S, Santos J E, Nonino C B (2012) Daily vitamin supplementation and hypovitaminosis after obesity surgery. Nutr J 28: 391-396 https://doi.org/10.1016/j.nut.2011.07.012

Dong HL, Wu HY, Tang Y, Huang Y W, Lin R Z, Zhao J, Xu X $\mathrm{Y}$ (2018) AMPK regulates mitochondrial oxidative stress in C2C12 myotubes induced by electrical stimulations of different intensities. J South Med Univ 38: 742-747. https://doi.org/10.3969/j.issn.16734254.2018.06.16

EL-Toweissy MY, Mohamed N A H, Abdel-Wahab W M (2013) The effect of melatonin and/or complex vitamin B1, B6, B12 in modulating epinephrine-induced stress in male rats. Braz Archi Biol Technol 56: 393-403. https://doi.org/10.1590/S1516-89132013000300007

Ferretti R, Moura E G, Dos Santos V C, Caldeira E J, Conte M, Matsumura C Y, Pertille A, Mosqueira M (2018) High-fat diet suppresses the positive effect of creatine supplementation on skeletal muscle function by reducing protein expression of IGF-PI3K-AKT-mTOR pathway. PloS One 13: e0199728. https://doi.org/10.1371/journal. pone.0199728

Gao X, Tian F, Wang X, Zhao J, Wan X, Zhang L, Wu C, Li N, Li J (2015) Leucine supplementation improves acquired growth hormone resistance in rats with protein-energy malnutrition. PloS One 10: e0125023. https://doi.org/10.1371/journal.pone.0125023

Gobl C S, Bozkurt L, Tura A, Leutner M, Andrei L, Fahr L, Husslein P, Eppel W,Willer A K (2017) Assessment of glucose regulation in pregnancy after gastric bypass surgery. Diabetol J 60: 2504-2513. https://doi.org/10.1007/s00125-017-4437-6

Gomes M J, Martinez P F, Pagan L U, Damatto R L, Cezar M D M, Lima A R R, Okoshi K, Okoshi M P (2017) Skeletal muscle aging: influence of oxidative stress and physical exercise. Oncotarget J 8: 20428-20440. https://doi.org/10.18632/oncotarget.14670

Halevy O, Piestun Y, Allouh,M.Z, Rosser B W C, Rinkevich Y, Reshef R, Rozenboim I, Lee M W, Reuveni Z Y (2004) Pattern of Pax7 expression during myogenesis in the posthatch chicken establishes a model for satellite cell differentiation and renewal. Develop Dynamics 231: 489-502. https://doi.org/10.1002/dvdy.20151

Hamrick MW, McGee-Lawrence ME, Frechette DM (2016) Fatty infiltration of skeletal muscle: mechanisms and comparisons with bone marrow adiposity. Frontiers Endocrinol 7: 69. https://doi.org/10.3389/ fendo.2016.00069

Hariri N, Thibault L (2010) High-fat diet-induced obesity in animal models. Nutr Res Rev 23: 270-299. DOI: https://doi.org/10.1017/ S0954422410000168

Hurrle S, Hsu W H (2017) The etiology of oxidative stress in insulin resistance. Biomed $J$ 40: 257-262. https://doi.org/10.1016/j. bj.2017.06.007

Ibrahim BM, Al-Saeed HF, Shalby AB (2017) Cardioprotective effects of vitamin B complex and Ethinyl Estradiol in ovariectomized rats. J Arab Soc Med Res 12: 39-45. https://doi.org/10.4103/jasmr. jasmr $6 \quad 17$

Ichinose T, Lesmana R, Yamamoto A , Kobayashi T, Shitara H, Shimoyama D, Takatsuru Y, Iwasaki T, Shimokawa N, Takagishi K, Koibuchi N (2014) Possible involvement of IGF-1 signaling on compensatory growth of the infraspinatus muscle induced by the supraspinatus tendon detachment of rat shoulder. Physiol Rep 2: e00197. https://doi.org/10.1002/phy2.197

Lipinski LC, Kmetiuk LB, Mathias PCF, Malta A, Favero GM, Ribeiro TA, Toledo A, Netto MRM, Rodrigues MRS (2017) Oral insulin improves metabolic parameters in high fat diet fed rats. Anais da Acad Brasileira Ciencias J 89: 1699-1705. https://doi.org/10.1590/00013765201720170040

Lupoli R, Lembo E, Saldalamacchia G, Avola CK, Angrisani L, Capaldo B (2017) Bariatric surgery and long-term nutritional issues. World J Diabet 8: 464-474. https://doi.org/10.4239/wjd.v8.i11.464

MacIntosh BR, Esau SP, Holash RJ, Fletcher JR (2011) Procedures for rat in situ skeletal muscle contractile properties. I Visualized Exp 56: e3167. https://doi.org/10.3791/3167

Mahdy MAA (2019) Skeletal muscle fibrosis: an overview. Cell Tissue Res 375: 575-588. https://doi.org/10.1007/s00441-018-2955-2

Makowska IJ, Weary DM (2016) The importance of burrowing, climbing and standing upright for laboratory rats. Royal Soc Open Sci J 3: 160136. https://doi.org/10.1098/rsos.160136

Martinez R, Kapravelou G, Lopez-Chaves C, Caceres E, Risco IC, Gonzalez CS, Upois I, Arrebola F, Galisteo M, Aranda P, Jurado ML, Porres JM (2019) Aerobic interval exercise improves renal functionality and affects mineral metabolism in obese Zucker rats. 
Am J Physiol Renal Physiol 316: F90-F100. https://doi.org/10.1152/ ajprenal.00356.2018

Mistry HD, Broughton PF, Redman CWG, Poston L (2012) Selenium in reproductive health. Am J Obstetrics Gynecol 206: 21-30. https:// doi.org/10.1016/j.ajog.2011.07.034

Müller MJ, Baracos V, Bosy-Westphal A, Duloo AG, Eckel J, Fearon KCH, Hall KD, Pietrobeli A, Sorensen TIA, Speakman J, Trayhum P, Visser M, Heymsfield SB (2014) Functional body composition and related aspects in research on obesity and cachexia. Obes Rev J 15: 640-656. https://doi.org/10.1111/obr.12187

Murphy M, Kardon G (2011) Origin of vertebrate limb muscle: the role of progenitor and myoblast populations. Curr Topics Develop Biol 96: 1-32. https://doi.org/10.1016/B978-0-12-385940-2.00001-2

Orsolic N, Landeka Jurcevic I, Dikic D, Rogic D, Odeh D, Balta V, Junakovic EP, Terzic S, Jutric D (2019) Effect of propolis on dietinduced hyperlipidemia and atherogenic indices in mice. Antioxidants J 8: 156. https://doi.org/10.3390/antiox 8060156

Petroni ML, Caletti MT, Dalle Grave R, Bazzocchi A, Gomez MPA, Marchesini G (2019) Prevention and treatment of sarcopenic obesity in women. Nutr J 11: 1302. https://doi.org/10.3390/nu11061302

Rabiu AM, Wale H, Garba K, Sabo AM, Hassan Z, Shugaba AI, Egesie UG, Odeh SO (2017) Body mass index of male and female Wistar rats following administration of leptin hormone after a dietary regime. Ann Bioanthropol 5: 22. https://doi.org/10.4103/aoba. aoba 1716

Roman W \& Gomes ER (2018) Nuclear positioning in skeletal muscle. Seminars Cell Develop Biol 82: 51-56. https://doi.org/10.1016/j. semcdb.2017.11.005

Saclier M, Cuvellier S, Magnan M, Mounier R, Chazaud B (2013) Monocyte/macrophage interactions with myogenic precursor cells during skeletal muscle regeneration. FEBS J 280: 4118-4130. https://doi.org/10.1111/febs.12166

Seebacher F, Tallis J, McShea K, James RS (2017) Obesity-induced decreases in muscle performance are not reversed by weight loss. Int J Obes 41: 1271-1278. https://doi.org/10.1038/ijo.2017.81

Sharma K, Mogensen KM, Robinson MK (2019) Pathophysiology of critical illness and role of nutrition. Nutr Clin Practice 34: 12-22. https://doi.org/10.1002/ncp.10232

Simioni C, Zauli G., Martelli AM, Vitale M, Sacchetti G, Goneli A, Neri LM (2018) Oxidative stress: role of physical exercise and antioxidant nutraceuticals in adulthood and aging. Oncotarget 9: 1718117198. https://doi.org/10.18632/oncotarget.24729

Sinclair P, Docherty N, le Roux CW (2018) Metabolic effects of bariatric surgery. Clin Chem 64: 72-81. https://doi.org/10.1373/ clinchem.2017.272336

Tallis J, James RS, Seebacher F (2018) The effects of obesity on skeletal muscle contractile function. J Exp Biol 221: jeb163840. https:// doi.org/10.1242/jeb.163840
Teive MB, Russi RF, Vieira DSC, Teive AM, Costa A, D'Acampora AJ (2012) Quantitative immunohistochemical analysis of duodenal ghrelin cells after sleeve gastrectomy in Wistar rats. Acta Cirurgica Brasilei ra 27: 595-599. https://doi.org/10.1590/S0102-86502012000900001

Tonkin J, Temmerman L., Sampson RD, Colon EG, Barberi L, Bilbao D, Schneider MD, Musaro A, Rosenthal N (2015) Monocyte/ macrophage-derived IGF-1 orchestrates murine skeletal muscle regeneration and modulates autocrine polarization. Mol Therap 23: 1189-1200. https://doi.org/10.1038/mt.2015.66

Trabal J, Forga M, Leyes P, Torres F, Rubio J, Prieto E, Codina A F (2015) Effects of free leucine supplementation and resistance training on muscle strength and functional status in older adults: a randomized controlled trial. Clin Int Aging 10: 713-723. https://doi. org/10.2147/CIA.S75271

Valenti V, Martin M, Ramirez B, Ambrosi JG, Rodriguez A, Catalan V, Becerril S, Lancha A, Femandez S, Cienfuegos JA, Burrell M A, Fruhbeck G (2011) Sleeve gastrectomy induces weight loss in diet-induced obese rats even if high-fat feeding is continued. Obesity Surgery 21: 1438-1443. https://doi.org/10.1007/s11695-010-0277-x

Wan JJ, Qin Z, Wang PY, Sun Y, Liu X (2017) Muscle fatigue: general understanding and treatment. Exp Mol Med 49: e384. https://doi. org/https://doi.org/10.1038/emm.2017.194

White Z, Milad N, Tehrani AY, Chen W W-H, Donen G, Sellers SL, Bernatchez P (2019) Angiotensin II receptor blocker losartan exacerbates muscle damage and exhibits weak blood pressure-lowering activity in a dysferlin-null model of Limb-Girdle muscular dystrophy type 2B. PloS One 14: e0220903. https://doi.org/10.1371/journal. pone. 0220903

Wu H, Ballantyne CM (2017) Skeletal muscle inflammation and insulin resistance in obesity. J Clin Invest 127: 43-54. https://doi. org/10.1172/JCI88880

Ibrahim MY, Nazmy WH, Ali FF (2016) Myopathy in type ii diabetes: metabolic and functional study in adult male albino rats. Al-Az̧ar Med J 45: 449-462. https://doi.org/10.12816/0029142

Zadka K, Palkowska-Gozdzik E, Rosolowska-Huszcz D (2018) The state of knowledge about nutrition sources of vitamin $\mathrm{D}$, its role in the human body, and necessity of supplementation among parents in central Poland. Int J Environ Res Public Health 15: 1489. https:// doi.org/10.3390/ijerph15071489

Zammit P S (2017) Function of the myogenic regulatory factors Myf5, MyoD, Myogenin and MRF4 in skeletal muscle, satellite cells and regenerative myogenesis. Seminars Cell Develop Biol 72: 19-32. https://doi.org/10.1016/j.semcdb.2017.11.011

Zhang Q, Qian ZY, Zhou PH, Zhang DL, He N, Zhang J, Liu YH, $\mathrm{Gu} Q$ (2018) Effects of oral selenium and magnesium co-supplementation on lipid metabolism, antioxidative status, histopathological lesions, and related gene expression in rats fed a high-fat diet. Lipids Health Dis 17: 165. https://doi.org/10.1186/s12944-018-08154 